\title{
Designing a Cognitive Speech Act Taxonomy for Dialogic Teaching and Learning: Explorative Action Games for Conceptual Change Learning
}

\author{
Sebastian Feller \\ A*STAR - Institute of High Performance Computing, Computational Social Cognition, 1 Fusionopolis Way, \#16-16 \\ Connexis, Singapore
}

\begin{abstract}
This paper explores the design of a cognitive speech act taxonomy for teaching and learning. The taxonomy and the theoretical framework that $I$ present here are about teaching and learning in a general sense. Other than for existing speech act taxonomies in this domain, the aim of the taxonomy proposed here is to represent and structure the cognitive processes involved in learning and link these processes to the language used in the teaching and learning interaction. Learning is thereby defined in terms of conceptual change (Thagard, 1992). The cognitive processes relevant for learning are describable in terms of what I call thinking patterns. Thinking patterns combine epistemic cognitive strategies, which I call enablers, with specific types of conceptual change. These strategies are derived from Aristotelian (1992) aitiae forming a heuristic structure to make sense of the world. Based on Weigand's (2010) Theory of Dialogic Action Games, I discuss the explorative action game as a possibility to implement this communicative framework in the teacher-learner interaction. I hold that learners can be guided to learning via so-called explorative speech acts that instantiate specific thinking patterns. These speech acts aim at what I call discovery speech acts as a response. Discovery is thereby framed in terms of a particular type of conceptual change evoked by a particular thinking pattern.
\end{abstract}

Index Terms-cognitive speech act taxonomy, conceptual change, teaching and learning interaction, explorative action game, dialogic knowledge building

\section{INTRODUCTION: GOING BEYOND EXISTING TAXONOMIES}

Computational linguistics has generated a number of speech act taxonomies that, at first sight, might seem useful for a teaching and learning speech act taxonomy. However, taking a closer look at these taxonomies like, for example, DIT+++ (http://dit.uvt.nl/, last date of access 9 May, 2013) it shows that a systematic link to relevant aspects of teaching and learning is missing. The taxonomies are structured along coarse-grained communicative actions that are too general to account for what is going on in a teacher-learner interaction, especially since they lack any sort of description of the non-verbal, i.e. cognitive level of communication. Integrating the cognitive level into the description is, in the case of teaching and learning, essential in order to understand what is going on when teacher and learner interact with each other and learning takes place.

Next to these general speech act taxonomies, researchers have set out to take a closer look at classroom language per se. For example, Sinclair \& Coulthard $(1975,1992)$ developed their so-called IRF model, which is short for initiation, response, and follow-up. The basic idea is that the teacher usually initiates communication about a topic by, for example, asking a question, the learner then responds to the teacher's initiation, and the teacher finally gives the learner feedback. Sinclair \& Coulthard's model is located within the arena of conversation analysis in the tradition of Sacks, Schegloff \& Jefferson (1974). Similarly, it does not fully reach out to the cognitive level of the interaction. The main focus of the model is on discourse structure and verbal behavior.

Recently there has been published a wave of practical teacher guides providing guidelines on how to use the "right" language in the classroom. Roser \& Denton (2010), for instance, focus on the use of open-ended questions in K-6 classrooms. They relate different types of questions to specific learning purposes like generating possible solutions, evaluating a plan or process, and planning the next steps (pp. 55ff.). Ferrell (2009) mentions Bloom's taxonomy of learning as a useful categorization of cognitive processes with a view to facilitating high level thinking and problem solving. Fisher (2005) identifies a number of cognitive strategies for critical thinking, which are based on Richard Paul's (1993) critical thinking framework. Similar to Roser \& Denton, these strategies revolve around a set of "right" questions including asking for clarification, seeking reasons or explanation, and forcing comparison.

In summary, past research on classroom language stands in the tradition of conversation or discourse analysis. More recent accounts tackling the cognitive level of teacher-learner interactions lack details, especially in explaining how exactly language relates to cognitive processes of learning. The focus is here mostly on critical discussion, in which already formed knowledge is questioned and existing viewpoints are exchanged. The question of how this knowledge is built in the first place remains largely unanswered. 
Tackling the question of teaching and learning, I propose in this paper a view of learning along a gradual communicative process which I have called elsewhere Dialogic Knowledge Building (Feller, 2013). This process of knowledge building is thereby facilitated by collaborative teaching and learning in which the learner teams up with the teacher or their peers with a view to finding a solution and tackling a topic together.

Taking this as starting point, I will give a systematic account of how to design a cognitive speech act taxonomy for teaching and learning. I will base the design of the taxonomy on what I call thinking patterns. These thinking patterns rest on a view of learning as conceptual change learning. They consist of epistemic patterns like cause and effect and specific types of conceptual change. Thinking patterns are the basic cognitive units of learning. Having identified these units, the question is how they can and should be instantiated in the teaching and learning interaction. Taking into account the basic assumptions of Self-Determination Theory (Deci \& Ryan, 1985) and a recent trend in educational science in favor of $21^{\text {st }}$ century skills (Bellanca \& Brandt, 2010), as well as Weigand's Theory of Dialogic Action Games (2010), I argue that the explorative learning game is a suitable communicative framework revolving around explorative and discovery speech acts. These speech acts instantiate the above-mentioned thinking patterns, providing a communicative structure for conceptual change learning in collaboration between the dialog partners.

\section{Why Cognitive States?}

Creating a cognitive speech act taxonomy leads sooner or later to the question of why we should be concerned with the interlocutors' cognitive states at all. Is it not language that we want to structure, and not cognition? In the end, cognition and knowledge building seem to belong to research fields like cognitive science or psychology, not linguistics perse.

However, we can only structure language if we first of all understand the cognitive states underlying it (Schalley \& Khlentzos, 2007). In a teaching and learning dialog, just like in any other type of dialog, the interlocutors use language for certain purposes. In other words, they use language to carry out actions. These actions, on the other hand, entail or presuppose cognitive processes. To give an example, let us take a look at conceptual metonymy. Here an instance from (Niemeier, 2004, p.111):

The Rolls-Royce left the gas station without paying.

It is immediately understood that it is the driver of the Rolls-Royce who has left without paying. The Rolls-Royce stands here merely as a place holder. This intended interpretation is not expressed on the verbal level but must first of all be inferred.

Levinson's (2000, p. 16) particularized conversational implicature (PCI) works similarly:

A: What time is it?

B: Some of the guests are already leaving.

PCI: It must be late.

In this short sequence, A infers the PCI against background information (including social conventions about how long guests usually attend a social event) which is not explicitly mentioned on the verbal level. Cognitive processes like these naturally occur in language use. Especially in the teaching and learning context, where learning ultimately takes place in the learner's head, essential parts of the interaction happen on the non-verbal level. We have to incorporate these things in the description of the interaction if we want to understand what is actually going on.

\section{Conceptual Change}

The cognitive states of the dialog partners are an essential part of the picture of what is going on in the teaching and learning interaction. These states are based on a network of processes of reasoning, understanding, and ultimately knowledge building or learning, in other words.

Conceptual Change Theory (CCT) (Thagard, 1992) provides the conceptual framework to grasp and track knowledge building. The basic assumption of CCT is that new knowledge is always built on top of existing knowledge. We are not blank slates but comprehend and cognize the world on the basis of what we already know (Pinker, 2002). What happens when we learn something is that we change or revise our existing knowledge. In CCT this change takes place in three basic ways (cf. also Hewson, 1992, pp. 3f.): i) A concept is extended. ii) A concept is truncated. iii) A concept is partially revised, i.e. parts of it are replaced with new parts.

Let us take a closer look at each of these three ways. To give an example, we imagine the following situation: a student in primary school learns about red blood cells. Let us suppose that the existing knowledge of the student does not go any further than a rough idea of something that is red. The teacher now shows the student a cartoon depicting red blood cells in an anthropomorphic way. The cells in the cartoon have human like features. For example, they stand on two feet, have two arms and two legs, a head and face. She tells the student that red blood cells go to the lungs where they pick up some stuff called oxygen. The blood cells then carry the oxygen to other body parts where it is needed to create energy. All this information including the outer appearance and anatomy of the cartoon figures, the transportation of oxygen and the creation of energy in other body parts, is added to the student's existing conceptualization of the red blood cell. Hence we are dealing here with i) concept extension. 
Some years pass by and our student finds herself in the high school biology course. Here the teacher shows her a scan of red blood cells taken with an electron microscope.

The student infers that the anthropomorphic features presented in the cartoon are not real but merely metaphorical and discards them from his existing red blood cell concept. She also deletes all the features that are indirectly associated with the metaphor like a red blood cell can think, talk, and walk like a normal human being. In addition, the teacher tells the student that red blood cells are biconcave cells that contain a substance called hemoglobin, which is a protein that can bind oxygen and gives the cells their typical red color. The student thus replaces the metaphoric representation with this new conceptualization. The basic function of transporting oxygen to body tissue remains intact, however. This is a clear case of iii) concept revision.

Moving on to university, our student learns that red blood cells come into existence in the bone marrow and last for about 100-200 days before they cease. This is new information that she adds to her existing concept, in other words, i) concept extension. The professor furthermore tells her that, compared to other kinds of cells, red blood cells do not have a cell nucleus and miss also most organelles to load up as much hemoglobin as possible. These are idiosyncrasies that the student had not known of before. The existing concept is thus ii) truncated accordingly.

It is these three types of conceptual change that are at the core of learning. In the next section, we will look into some of the enabling cognitive factors of conceptual change, i.e. those cognitive processes that scaffold and facilitate conceptual change along these lines.

\section{Aitiae: A Basic Epistemological Structure}

In addition to the processes described in CCT there are cognitive processes that help us represent and make sense of the world. These processes are epistemic, i.e. they enable us to form a mental picture or conceptualization of the world and the objects therein.

These epistemic processes are the enabling factors of conceptual change. They form the "critical mass" of concepts by creating a conceptual tension between existing knowledge and knowledge to be that eventually discharges as conceptual change. I will henceforth refer to these cognitive processes as enablers. My view of enablers is thereby inspired by Dahlgren's (1988) Naïve Semantics in general and what she calls kind types and feature types in particular. As Dahlgren (1988, pp. 66f.) points out, kind types are the basic categories for so-called kind terms, i.e. terms that refer to "real classes of real objects". Kind types predict feature types of kind terms; in other words, they constrain what sorts of features a kind has. For example, "[t]he kind type ANIMAL predicts that elephant will have certain types of properties, such as habitat, which secretary lacks [...]” (p. 71). I conceptualize enablers along similar lines: they predict how knowledge building takes place, i.e. the type of conceptual change the learner engages in when she learns.

However, Dahlgren's categorization is static and is therefore not suitable for coming to grips with conceptual change. Instead, we are in need of a more dynamic framework. Aristotle's (1992) aitiae provide an epistemic structure for distinguishing between different types of enablers. Aitiae have played a central role in epistemology, i.e. the science of knowledge, ever since. Aristotle introduced four different types of aitiae:

a) constitutive: relating to objects and its parts

1) A car has four wheels.

b) formal: defining what distinguishes an object within a larger domain

2) An elephant is grey just like a mouse but much bigger in body size.

c) telic: referring to an object's purpose or function, i.e. what it is used for

3) A car is for driving.

d) efficient: indicating forces outside of an object, causing change or movement or bringing it into existence

4) A car is assembled in a car factory.

According to Aristotle, these four aitiae or causes, in other words, lie at the heart of our understanding of the things in the world. They give an answer to the question Why? and are thus the basic building blocks of our understanding or definition of things. This is why the four aitiae provide a plausible categorization for enablers. As the basic building blocks of explanation, they, in a way of speaking, determine the cognitive "path" our conceptualization takes.

In the next section, we will look into the question of which enablers can be derived from which aitiae. We will then analyze how the different groups of enablers activate conceptual change and thus trigger learning.

\section{A. Deriving Enablers from Aitiae}

Having arrived at a basic epistemological structure in terms of aitiae, we are now in a position to derive correlating types of enablers as illustrated in Table 1 . 
TABLE 1.

DERIVING ENABLERS FROM AITIAE. “X” INDICATES THAT ENABLER AND AITIÊN CORRELATE
\begin{tabular}{|l|l|l|l|l|}
\hline enabler/aitia & constitutive & formal & telic & efficient \\
\hline part-of & $\mathrm{x}$ & & & \\
\hline has-a & $\mathrm{x}$ & & & \\
\hline general-specific & & $\mathrm{x}$ & & \\
\hline specific-general & & & $\mathrm{x}$ & \\
\hline similar-different & & $\mathrm{x}$ & & \\
\hline is-for & & & $\mathrm{x}$ & \\
\hline cause-effect & & & & $\mathrm{x}$ \\
\hline effect-cause & & & & $\mathrm{x}$ \\
\hline antecedent-consequent & & & & $\mathrm{x}$ \\
\hline is-at & & & & $\mathrm{x}$ \\
\hline
\end{tabular}

Let us begin with a) constitutive. Considering the parts or components of an object, conceptualizations run along the following lines:

A) part-of relation: this relation defines an object as being part of a larger object. Together with the other parts, it constitutes the larger object. Rephrasing 1) gives the following example:

5) The wheel is part of the car.

B) has-a relation: this relation is corresponding to A), defining the relation from the opposite end. It is now the larger object which is at the center of the conceptualization. Consider the example from earlier:

1) A car has four wheels.

We continue with enablers under b) formal. Here we can distinguish between the following relations:

C) general-specific relation: here we are dealing with the relation between an umbrella concept, i.e. the hyperonym, and its subordinate or hyponym. The relation between hyperonym and hyponym is conceptual inheritance: the hyponym inherits all the features from the hyperonym. In addition, it possesses some additional features which are only presupposed as potentials in the hyperonym but not per se part of it. The following example illustrates this:

6) A car is a vehicle with four wheels.

D) similar-different relation: this relation is similar to C). It is based on an intersecting set of features of two or more objects contrasted against a subset of object-specific features. As opposed to C), where the intersecting set of features is derived from the hyperonym, here the intersecting set is derived from a concept on the same conceptual level as the base concept. Here an example:

7) A Porsche is like a Ferrari made in Germany.

Let us move on to c) telic.

We can construct the relation in 6) from the other end, resulting in the new relation E) specific-general.

8) A car is a vehicle.

In contrast to 6), in 8) the hyponym is defined in terms of the more abstract hyperonym. Specific features are not mentioned. It is here only basic functions common to all vehicles like the transportation function which are entailed by this conceptualization.

F) is-for relation: this relation refers explicitly to the purpose or function of an object. To give an example, consider 3) discussed earlier:

3) A car is for driving.

Last, we take a look at d) efficient. These are the correlating relations:

G) cause-effect relation: this relation points to a force outside the object, i.e. the cause, which brings something about, namely the effect. The following sentence illustrates this relation:

9) The street is wet because it was raining.

This relation can be turned around, resulting in $\mathrm{H}$ ) effect-cause:

10) It was raining, so the street is wet.

In a wider sense, we can also derive temporal relations from d) efficient. For example, I) antecedent-consequent relation:

11) First I went to the bank, then I visited Laurie.

The event structure is, similar to the causal structure in 9) and 10), an external "force". I hold the same for location or $\mathrm{J})$ is-at relation:

12) The car is parked on the other side of the building.

In the end, correlating time and location with this and not another aitien or even a totally new epistemic category is a heuristic decision. I do not claim that any of the above-mentioned correlations reflects cognition as it really is. Rather, the proposed structure is a working hypothesis for coming to grips with the cognitive processes in learning from a theoretical point of view.

\section{B. Thinking patterns: Correlating enablers with conceptual change}

Having derived the enablers A) to J) from the aitiae, we can now tackle the question of how enablers are connected to conceptual change. The basic assumption thereby is that we can use specific enablers in communication to potentially trigger particular types of conceptual change. The word 'potentially' is here of paramount importance. There are a 
number of other correlating factors beyond the scope of aitiae and enablers. For example, one such factor is the learner's existing knowledge, among others. An enabler will not result in conceptual change, if the learner already possesses the knowledge entailed by the enabler. A precondition for conceptual change thus is that the learner has an actual need to change his existing knowledge. Depending on the exact type of conceptual change, this need differs in nature. As for i) concept extension, the need comes in the form of a knowledge gap. In the case of ii) concept truncation, the learner must be aware that an existing concept in her knowledge base contains superfluous information, which should be crossed out. In addition, iii) concept revision presumes that the learner is aware that parts of an existing concept are inaccurate and should be replaced with new information.

Table 2 gives an overview of the specific correlations between enablers and conceptual change:

TABLE 2.

THE RELATION BETWEEN ENABLERS AND SPECIFIC TYPES OF CONCEPTUAL CHANGE. “ $X$ ” INDICATES THAT THE ENABLER DIRECTLY TRIGGERS THE CORRESPONDING TYPE OF CONCEPTUAL CHANGE. “(X)” INDICATES THAT THE ENABLER MUST BE SPECIFIED FURTHER IN ORDER TO TRIGGER THE CORRESPONDING TYPE OF CONCEPTUAL CHANGE.

\begin{tabular}{|l|l|l|l|}
\hline enabler/conceptual change type & extension & truncation & revision \\
\hline part-of & $\mathrm{x}$ & $(\mathrm{x})$ & $(\mathrm{x})$ \\
\hline has-a & $\mathrm{x}$ & $(\mathrm{x})$ & $(\mathrm{x})$ \\
\hline general-specific & $\mathrm{x}$ & $(\mathrm{x})$ & $(\mathrm{x})$ \\
\hline specific-general & $\mathrm{x}$ & $(\mathrm{x})$ & $(\mathrm{x})$ \\
\hline similar-different & $\mathrm{x}$ & $(\mathrm{x})$ & $(\mathrm{x})$ \\
\hline is-for & $\mathrm{x}$ & $(\mathrm{x})$ & $(\mathrm{x})$ \\
\hline cause-effect & $\mathrm{x}$ & $(\mathrm{x})$ & $(\mathrm{x})$ \\
\hline effect-cause & $\mathrm{x}$ & $(\mathrm{x})$ & $(\mathrm{x})$ \\
\hline antecedent-consequent & $\mathrm{x}$ & $(\mathrm{x})$ & $(\mathrm{x})$ \\
\hline is-at & $\mathrm{x}$ & $(\mathrm{x})$ & $(\mathrm{x})$ \\
\hline
\end{tabular}

\section{Concept Extension}

Let us begin with A), the part-of relation. Returning to 5) The wheel is part of the car., we can split up the complex proposition expressed in 5) into smaller parts: on the one hand, the base concept "the wheel" and, on the other, "the car" which extends the base concept. "the wheel" is here put into its broader "ecological" context. This enabler thus correlates with i) conceptual extension.

B) has-a relation works similarly. Compared to A), base concept and extension are switched: in the corresponding example 1) it is "a car", which is now the base concept, and "four wheels" extends this concept.

C) general-specific also adds information to the base concept. As illustrated in 6), new information is added in terms of the hyperonym "vehicle" and the specific feature "four wheels" of the hyponym. E) specific-general works along similar lines, except that specific features are not provided. However, information is provided in the form of the set of general features inherited from the hyperonym.

D) similar-different differs only slightly from C). While in C) information is added by the hyperonym, in D) two or more objects of the same hierarchical level are compared with each other. Idiosyncratic features that distinguish the base concept in the contrast relation are added to the base concept. We can see in 7) how the base concept "Porsche" is specified by the intersecting set of features it shares with "Ferrari" and the additional distinct feature "made in Germany".

Moving on to F) is-for relation, the base concept is extended by the object's specific function (as in 3 earlier).

As for $\mathrm{G}$ ) cause-effect, the base concept, i.e. the effect, is specified by the cause and vice versa for $\mathrm{H}$ ) effect-cause.

The temporal order expressed in 11) by I) antecedent-consequent relation specifies the events expressed in the proposition. The events are presented in a sequence which is not inherent in the single events per se. This is why the chronological order can be changed without causing any sort of contradiction. For example, First I visited Laurie, then I went to the bank works just as fine.

Location is another case of concept extension. As illustrated in 12), the base concept "the car" is extended through J) be-at relation by the locative information "on the other side of the building".

\section{Concept Truncation}

Concept truncation happens when the propositional content of enablers is fully or partially negated. To give an example, let us take a look at our earlier case under E) specific-general and contrast it with a slightly extended version:

6a) A car is a vehicle.

6b) A car is a vehicle, but this car does not run anymore.

What happens in 6b) is that the inheritance of hyperonymical features is restricted by the subordinate clause. In this case, it is the generic transportation function which is negated for the particular car referred to in the example.

To give another example, we go back to $\mathrm{H}$ ) effect-cause:

10a) It was raining, so the street is wet.

10b) It was raining, but the street is dry (i.e. not wet).

In this case, while 10a) expresses the "natural" or expected entailment relation of the presented state of affairs, 10b) negates the expected consequence. The conjunction "but" thereby implies the contradictory relation between the fact 
that it was raining and the unexpected outcome of the street still being dry. The original entailment relation in 10a) is thus truncated to a sequence of events that contradicts the entailment expressed in 10b).

In summary, the examples illustrate how negation of parts or whole of an enabler's proposition correlates with concept truncation. Enablers trigger concept extension but the extension is constrained through negating selected features of the extended concept. Truncation is thus a specification of extension which can be applied to all extension enablers.

\section{E. Concept Revision}

All enablers can be used for concept revision by replacing parts of the propositional content of an enabler with new information. This works for all enablers alike. As space is limited, we select the following example for illustration.

10a) It was raining, so the street is wet.

10c) A fire truck was leaking water, so the street is wet.

Changing 10a) to 10c) revises the original proposition by replacing the cause [it was raining] with the new cause [a fire truck was leaking water]. The second part of the proposition [the street is wet] remains intact.

The type of conceptual change between 10a) to 10c) is thereby totally different compared to the one between 10a) and 10b). While changing 10a) to 10b) causes a complete shift in the quality of the relation expressed in the proposition, in the case of 10a) and 10c) the epistemic relation remains the same. The cause changes; however, we are still dealing here with an effect-cause relation as a whole.

In the next section we will have a look at how language is connected to the enabler-conceptual change patterns, henceforth thinking patterns. The main question is how and what language correlates with what kinds of thinking pattern? An answer to this question will help us understand how thinking patterns can be instantiated in communication and what linguistic means are available to the dialog partners to instantiate conceptual change learning.

\section{Excursus: Pedagogical Considerations}

In order to get a better understanding of how language relates to conceptual change learning and what kind of language should be used in teaching and learning interactions, we need to take a closer look at teaching and learning as such.

From a pedagogical point of view, teaching and learning have undergone some severe changes during the recent decades. There has been a drastic shift from content- and teacher-based to skill- and learner-based learning. One of the recent most impactful changes runs under the label $21^{\text {st }}$ century skills. These skills include critical thinking, creativity, communication, and collaboration, amongst others. From this point of view, learners should be able to construct knowledge actively through critical assessment, evaluation, and an exchange of ideas and viewpoints.

Especially collaborative learning and dialogic teacher-learner interactions have been investigated with regards to their effects on knowledge building and learner performance. Many findings point out that collaborative and dialogic learning settings support successful long term learning and help facilitate deep understanding, as well as high-level thinking, and creativity (e.g., Benware \& Deci, 1984; Grolnick \& Ryan, 1987; Kage \& Namiki, 1990; Koestner, Ryan, Bernieri \& Holt, 1984; Vansteenkiste, Ryan \& Deci, 2008).

The main assumptions behind $21^{\text {st }}$ century skills tie in with Deci \& Ryan's (1985) Self-Determination Theory (SDT). The basic idea of SDT is that every human being has three fundamental psychological needs: autonomy, competence, and relatedness, henceforth ACR. This means that, in general, everyone wants to make their own choices, be able to find a solution to a problem, and be respected and liked by the people she is surrounded by. Fulfillment of all three needs is necessary for what Deci \& Ryan call "internalization" of an activity, i.e. that the person engages in the activity for its own sake. The person regards an internalized activity as intrinsically valuable and feels joyful and happy while engaging in it.

Let us sum up what we have discussed so far: we have said earlier that learning happens when the learner changes her existing knowledge. Thereby, knowledge is defined in terms of concepts that are stored in the learner's knowledge base. Drawing on Conceptual Change Theory, we have furthermore laid out three specific ways in which the learner might change her existing concepts: concept extension, concept truncation, and concept revision. On top of this, I defined so-called enablers which I derived from Aristotle's aitiae, providing a heuristic epistemological foundation for our conceptualizations of the world and the things therein. Enablers are, in a way of speaking, thinking pointers which indicate how existing concepts are changed. Last, we looked into pedagogical considerations on learning and argued that collaborative and dialogic learning settings help boost higher level thinking and deep reasoning.

Having arrived at these insights, the question remains how all this can be implemented in the teacher-learner interaction. What kind of language scaffolds conceptual change learning and collaborative learning? I will deal with these questions in the remainder of this paper.

\section{TEACHER-LEARNER INTERACTION AS ACTION GAME}

The cognitive speech act taxonomy that I propose grounds in a view of teacher-learner interactions in terms of dialogic action games. Based on Weigand's Mixed Game Model (MGM) (2010) the action game is the smallest 
functional unit of communication. It consists of an initial communicative action by one speaker and the subsequent reaction by the dialog partner (see Fig. 1).

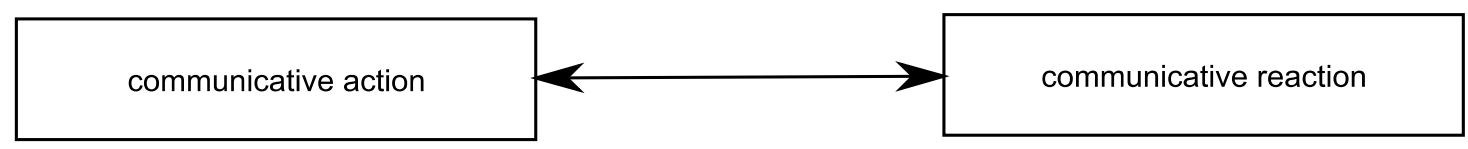

Fig. 1. The dialogic action game. This figure illustrates the minimal unit of communication consisting of communication action and reaction. As indicated by the double arrow, action and reaction are mutually related to each other.

This pair of communicative action and reaction is embedded within the speakers' "worlds" incorporating cognitive, perceptive as well as emotive states of the interlocutors, as well as their culture, societal norms, personal habits, preferences, and background knowledge, to name a few. As we will see in the next section, this holistic view of language and language use provides an appropriate foundation to conceptualize teaching and learning interactions in accordance with $21^{\text {st }}$ century skills in general and SDT's ACR in particular.

Adopting the concept of the action game to teacher-learner interactions, we arrive at learning-specific pairs of communicative actions and reactions that are used by the speakers for specific ends. We will see later on what these ends look like in more detail and which particular communicative actions and reactions correlate with them.

Dividing teaching and learning into different styles along a spectrum with the two end points lecturing (teachercentered, content based learning) vs. collaborative learning (learner-centered, skill based learning), we can assume distinct types of action games along this scale. Closer to the lecturing end point we can think of an action game in terms of an ostensive learning game. In this game, the teacher conveys information to the student simply through definitions. The student is in a passive role. She is confined to reacting, whereby reaction is limited to what I call acknowledging. By acknowledging I mean that the student uptakes information without questioning, challenging, or reflecting critically; in other words, classic rote learning.

A related type of game which is located slightly closer towards the discovery end point of the spectrum is the argumentative game. In this game the student questions the information provided by the teacher. Her role is here more active. The student might, for example, contrast what the teacher says with other viewpoints including her own.

Moving towards the discovery end of the spectrum, we find the explorative game. In this type of game, information is not simply conveyed or compared. Here teacher and learner explore a topic collaboratively. The teacher introduces the topic, for example, through what I have called elsewhere "deep explanation questions" (Feller, 2013). Deep explanation questions are questions that facilitate high level thinking and deep reasoning in the student. They entice the student in finding complex answers with a high level of detail and innovative solutions.

Explorative games make the type of action game that suits best the assumptions of SDT as well as $21^{\text {st }}$ century skills discussed earlier. In the remainder ('remainder'?) of this paper I will therefore shift the main focus on this type of action game.

\section{A. Explorative Action Games and Conceptual Change}

Explorative action games facilitate conceptual change by means of activating thinking patterns. Thinking patterns are what I call the enabler-conceptual change pairs listed in Table 2. The thinking patterns are correlated with "the language of the game", i.e. the interlocutors use language in order to "carry out" the thinking patterns collaboratively in the action game.

The main question now is what kinds of communicative actions we find in an explorative teaching and learning action game and how these actions are organized. Following Searle's (1969, pp. 31ff.) speech act formula F(p), where F represents the illocutionary function of the speech act and $\mathrm{p}$ the propositional act, the function $\mathrm{F}$ is what we need to define now. $\mathrm{F}$ is the purpose or action correlating with the speech act, i.e. what the speaker is doing with it. In this sense the question here is: what kinds of actions are the speakers carrying out in an explorative action game.

There are some candidates from existing speech act taxonomies. For example, in Weigand's (2010, pp. 147ff.) dialogic speech act taxonomy we find the speech act type EXPLORATIVE. She further divides this type into three subtypes: EXPLORATIVE[knowledge], EXPLORATIVE[action], and EXPLORATIVE[certainty]. All three types are a good starting point for laying out a more complete taxonomy.

Let us take a closer look at each single type of EXPLORATIVE. The speaker uses EXPLORATIVE[knowledge] to request information about the world. This information is needed for conceptualizing things. A question like, for example, What is an electron? falls under this category.

EXPLORATIVE[action], on the other hand, is about requesting information needed for action. What do I need to do in order to take a voltage reading? is a good example for this type of explorative. The speaker requests information that helps her to achieve a particular goal.

The third type, EXPLORATIVE[certainty], is about finding out whether one's belief about the world matches the stateof-affairs. To give an example, the speaker might ask Are you sure? or You really do not know the answer?. The provided information in the response helps assess how certain it is that something has happened in the past or is about to happen in the future. 
Basing the explorative action game on these three illocutionary functions, the question arises now if and, if so, how each of them is connected to the thinking patterns in Table 2.

\section{B. The Connection between Exploratives and Thinking Patterns}

As discussed earlier, the explorative action game consists of action and reaction, i.e. an initial and a reactive speech act. In the following sections we will take a closer look at these two speech acts and how they are connected to the thinking patterns discussed earlier.

With reference to Weigand (2010), I have identified three types of exploratives that are at the heart of explorative teaching and learning action games: EXPLORATIVE [knowledge], EXPLORATIVE [action], and EXPLORATIVE[certainty]. As already suggested by the name, all exploratives are used to explore. The difference between the distinct speech act types is, however, what exactly the speakers set out to explore. The answer is to be found in the thinking patterns we defined earlier. Each explorative is connected in their own distinct ways to the thinking patterns. The question now is what this connection looks like exactly.

I will give an example of how this connection unfolds against the backdrop of one selected thinking pattern. This suffices to outline the basic rationale behind the design of the cognitive speech act taxonomy. A discussion of all thinking patterns clearly exceeds the limits of this paper.

\section{The Initial Speech Act: Explorative [Knowledge]}

In this section we will address the question of how exploratives are "connected" to the thinking patterns. What I have in mind here can be best illustrated against Searle's formula F(p). F stands for the illocutionary function of the speech act, i.e. the purpose of the speech act or what the speech act is used for. $\mathrm{p}$ is the propositional act, which consists of both reference and predication. For example, a noun phrase like "my car" refers to a particular object in the world, which is represented as the concept [my car] in the speaker's knowledge base. For example, "is red" might then be used to predicate the color red to the concept [my car].

For illustration purposes, let us consider the thinking pattern C) general-specific - conceptual extension. How can this pattern be instantiated in an explorative action game? In other words: how does the EXPLORATIVE that the speaker uses to bring this pattern into play look like? Based on Searle's formula, we can demarcate the speech act as follows:

EXPLORATIVE[knowledge] (general-specific) $\rightarrow$ communicative means (open-ended)

Fig. 2 shows how the different parts are connected to each other:

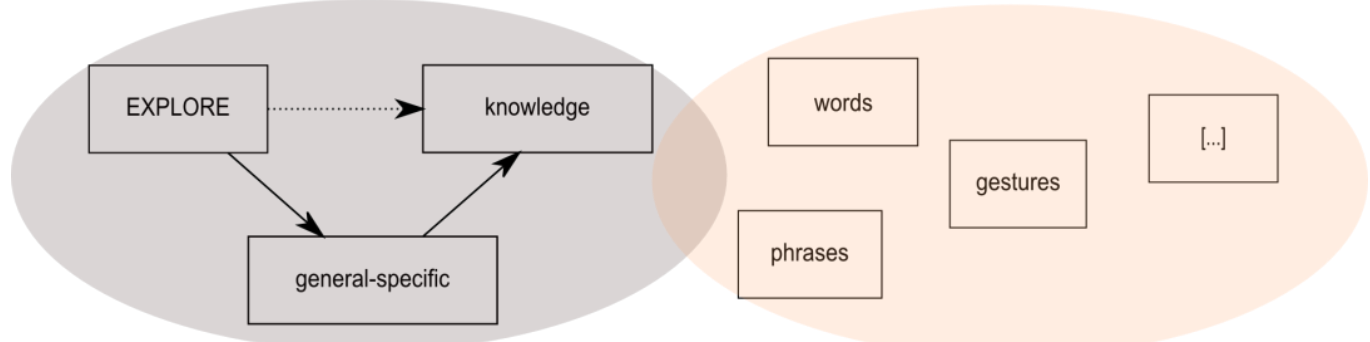

Fig. 2. The correlation between the function and the expression side. The explorative speech act on the left is instantiated in language use by a potentially open-ended set of communicative means as represented on the right.

As discussed earlier, EXPLORE in Fig. 2 denotes the illocutionary function of the speech act, which is in this case exploring a topic. More precisely, exploring is directed towards knowledge for knowing as indicated by [knowledge].The enabler is in the place of the propositional act $\mathrm{p}$. We can thus say that the explorative speech act is about the enabler: the speech act is used to introduce the enabler as the subject of exploration. The dashed arrow thereby indicates the indirect connection between the communicative function and knowledge. The solid arrows indicate a direct link between the propositional act and the communicative function, as well as a quasi-direct link between the propositional act and knowledge. What I mean by quasi-direct will be explained in section 6.5.

The right side of Fig. 2 refers to how this speech act is instantiated in the communication. As indicated by the intersecting set, the functional side EXPLORATIVE (general-specific) correlates to set of communicative means which is a potentially open-ended. These means include not only lexical expressions but also cognitive and perceptive means. For example, the speaker might use gestures or refer to things in her environment and draw on inferences with reference to given background knowledge not expressed verbally.

As the expression side is potentially open-ended, any taxonomy can provide only an exemplary snapshot of communicative means available in real life communication. It is thus the functional side which provides the main structure for communicative means in explorative action games.

\section{The Reactive Speech Act: Discovery}

We have seen how one part of the thinking pattern, namely the enabler, is instantiated in the propositional act $p$ of the explorative speech act. Conceptual change is part of the reactive speech act in the action game: the discovery speech act. Following Searle's formula again, we represent this speech act as follows: 
DISCOVERY [knowledge] (general-specific) $\rightarrow$ communicative means (open-ended)

Fig. 3 gives a more detailed account of the relations that hold between the different parts:

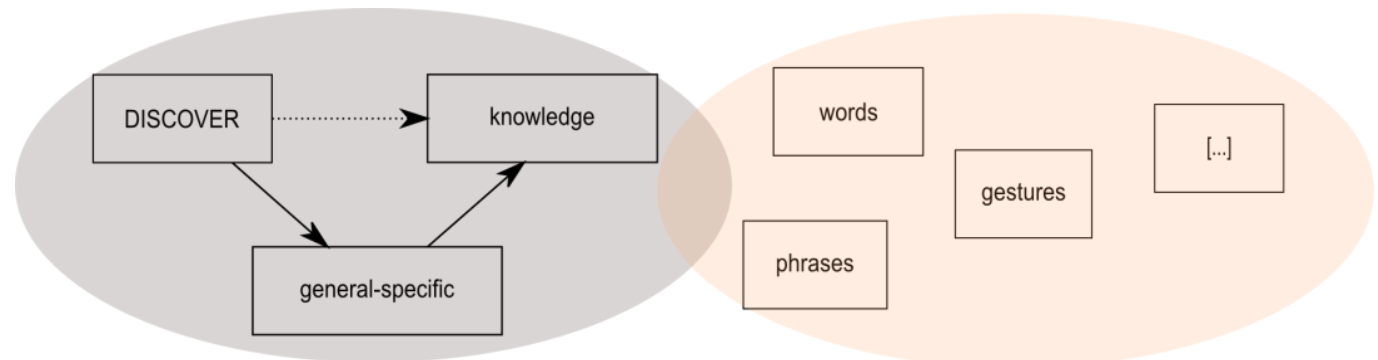

Fig. 3. The correlation between the function and the expression side. The explorative speech act is instantiated in language use by a potentially openended set of communicative means.

The illocutionary function of this speech act is DISCOVER, meaning that the speaker discovers new information. As a reaction towards EXPLORATIVE [knowledge], this speech act is about knowledge for knowing. The manner of discovery is thereby described by the propositional act (general-specific). The speaker presents what she discovers along the lines of this type of enabler.

\section{E. Conceptual Change as Perlocutionary Effect}

So far we have seen how the enablers are instantiated in the speech acts of the action game. But what about the exact nature of the connection between the speech acts, i.e. both the explorative and the discovery speech act, and knowledge as presented in Fig. 2 and 3? I have argued earlier that knowledge is built through conceptual change. In the action game conceptual change is part of the so-called perlocutionary effect of the explorative speech act.

With a view to getting a better understanding of what that means, let us take a closer look at perlocution. In Speech Act Theory, perlocution is defined as the psychological effect a speech act causes in the addressee (Peccei, 1999). As for the explorative speech act, it is the particular type of conceptual change correlating with the enabler in the propositional act $\mathrm{p}$ that is in the role of the perlocution. The traditional definition of perlocution furthermore holds that the psychological effect is beyond the immediate control of the speaker.

This is true in the case of the explorative speech act. The speaker expects the type of conceptual change correlating with the enabler in $p$ to unfold in the hearer. If this actually happens is, however, outside the direct influence of the speaker. Other factors partly determine the hearer's reaction including her perspectivization of a given problem, her existing knowledge, her comprehension of the problem, the history of the interaction, her learning style, which includes her personal learning preferences, etc.

We can illustrate this view of conceptual change as perlocutionary effect as follows:

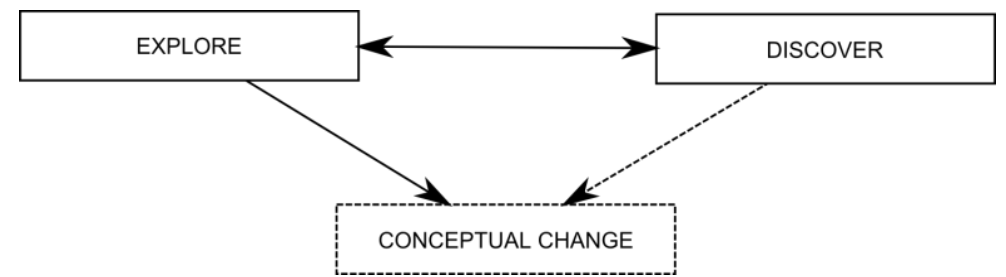

Fig. 4. Conceptual change as perlocutionary effect. This figure illustrates the connection between the minimal action game, i.e. the mutually related explorative and discovery speech acts, and conceptual change. As indicated by the continuous arrow, the explorative speech act expects that the discover speech act yields conceptual change. On the other hand, if the discovery speech act really results in conceptual change is contingent on "external" factors, which is indicated by the dashed arrow.

Action and reaction are mutually related to each other and indirectly inked via conceptual change. The dashed arrow thereby indicates that the link between DISCOVER and conceptual change is what I called earlier quasi-direct. The link between EXPLORE and conceptual change is more immediate in the sense that the speaker expects conceptual change to take place.

\section{F. An Example: The Electron Action Game}

Having arrived at a conceptualization of the general explorative action game for teaching and learning interactions, we will now take a look at a concrete example.

First of all, an action game is always about a specific topic:

TOPIC [EXPLORATIVE(enabler)] $\longleftrightarrow$ TOPIC[DISCOVERY(conceptual change)] $]^{1}$

We can thus place the action game in the context of a common topic:

\footnotetext{
${ }^{1}$ In the remainder of this paper the speech acts are about knowledge for knowing, which was indicated earlier by [knowledge] in the illocutionary function F. For reasons of readability, I will henceforth not indicate this explicitly in the figures.
} 


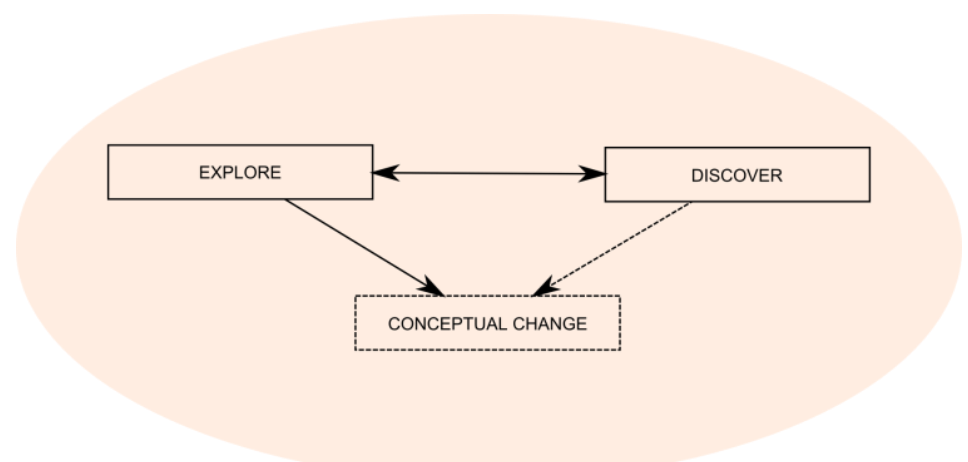

Fig. 5. The directed action game. As indicated by the shaded background, an explorative action always grounds in a specific topic, i.e. the subject domain that is being explored in the action game.

For illustration purposes, let us hypothesize a teacher-learner interaction about electrons, more precisely the function of electrons. This directed action game looks like this:

\section{ELECTRON [EXPLORATIVE(is-for)] $\longleftrightarrow$ ELECTRON[DISCOVERY(is-for)]}

Initiating the explorative action game, the speaker must instantiate this speech act in the communication. As discussed earlier, the set of communicative means is potentially open-ended. To give an example, let us assume that the speaker asks questions that request information about the functions of electrons. These questions might be of the form: What are electrons for?, What do electrons do/cause/result in?, or Why are electrons needed/used/applied here?

The right side of the action game, i.e. the reaction follows a similar structure. TOPIC indicates what the reaction is about. TOPIC for DISCOVERY should thereby match TOPIC for EXPLORATIVE, i.e. both speakers share and act on common ground. In the given case, DISCOVERY as the reactive speech act provides here a propositional act containing information about the function of an electron. This information thus bears the potential for extending the existing concept [electron] in the speaker's knowledge base. By speaker I mean here the learner, i.e. the dialog partner who carries out the speech act ELECTRON [DISCOVERY(is-for)]. As discussed earlier, if the speaker extends the concept in fact, is contingent on multiple other factors that lie beyond the immediate scope of the action game like the learner's existing knowledge, as well as her emotive and motivational states during the interaction, among others.

To give some examples, possible answers could be: Electrons make atoms bond, The function of electrons is to make atoms bond, or Electrons cause atomic bonding. It is important to note that, similar to the explorative speech act, the discovery speech act correlates with a potentially open-ended set of communicative means. We should keep in mind, that it is the functional design of the cognitive speech act taxonomy which lays the basis for structuring language, i.e. communicative means. What kinds of communicative means speakers use or should use to instantiate a particular speech act is left to be investigated by empirical analysis of authentic language data.

\section{Designing the Cognitive Speech Act Taxonomy}

Bringing together what we have learnt in the previous sections of this paper, the following basic structure emerges for designing the cognitive speech act taxonomy for teaching and learning:

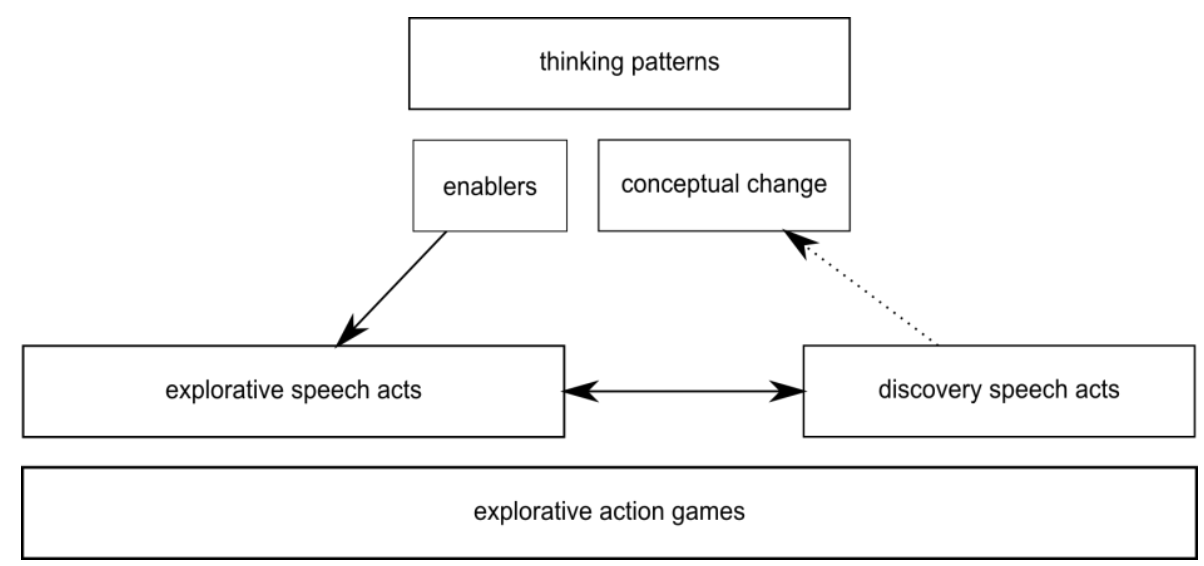

Fig. 6. The basic building blocks of the cognitive speech act taxonomy. This figure shows how the different units of the function side are connected to each other. Continuous arrows stand here for direct relations, while dashed arrows indicate expected but not necessary relations.

As Fig. 7 shows, the taxonomy consists of two interrelated tiers: thinking patterns and explorative action games, or, in other words, the level of cognition and its connections to the level of communication. As indicated by the arrows, the levels are directly connected via enablers and explorative speech acts: as discussed earlier the speaker uses explorative speech acts to instantiate exploration of a topic along specific enablers. The discovery speech act and the explorative 
speech act are mutually related to each other, which is indicated by the double arrow. In addition, the discovery speech act is indirectly linked to conceptual change. As mentioned earlier, conceptual change is a kind of perlocutionary effect, which is not under the immediate control of the dialog partners. It is contingent on factors like the hearer's existing knowledge, her learning style and comprehension of a given problem or state of affairs, as well as her motivation to learn, among others.

This two-tiered structure is the foundation for the basic design of the cognitive speech act taxonomy. The taxonomy is a network of explorative action games that revolve around different enablers potentially entailing specific types of conceptual change. Adding to the taxonomy might thereby come in two different forms: top-down and bottom-up. Topdown works along the following lines:

- Enabler and topic as starting points determine explorative speech act, for example, is-for relation and electrons as topic entail explorative speech act like ELECTRON[EXPLORATIVE(is-for)].

- Explorative speech act determines discovery speech act. For example, ELECTRON [EXPLORATIVE(is-for)] asks for ELECTRON[DISCOVER(is-for)] as response.

- Discovery speech act determines conceptual change. For example, ELECTRON [DISCOVER(is-for)] (potentially) implies concept extension.

In summary, these steps originate from the question: how do I teach the function of electrons?

This question can also be turned upside down: how do I learn the function of electrons? In order to come to an answer we turn the order of steps around:

- Selected topic and the desired kind of conceptual change determine discovery speech act. To give an example, concept extension and ELECTRON combine to ELECTRON [DISCOVER (enabler)].

- Discovery speech act determines explorative speech act. For example, ELECTRON [DISCOVER (enabler)] expects ELECTRON [EXPLORATIVE (enabler)] as initiation.

- Last, we select the "direction" of exploration by means of installing a particular enabler. For example, if it is the function of electrons which is to be explored, we select the is-for relation as enabler, yielding ELECTRON [EXPLORATIVE (is-for)].

The bottom-up approach starts off from authentic language data. Here we add action games to the taxonomy by looking at teacher-learner interactions from real-life. Taking the basic building blocks of the taxonomy as a blueprint for analysis, we search interactions for pairs of explorative and discover speech acts. In the second step, the identified speech acts are broken down into their components: TOPIC, as well as the enabler expressed in the propositional acts of the speech acts. In addition, we infer the expected type of conceptual change from the exact make up of the propositional act.

In summary, both approaches, i.e. top-down as well as bottom-up, add new entries to the taxonomy in the form presented in Fig. 6. The overall scale and granularity of the taxonomy is thereby a heuristic matter. Factors like the taxonomy's purpose, usability, and the user's expert level determine how detailed and extensive the level of description should be.

The proposed design can be put to use in a number of different application areas. It might lay the foundation for the modeling of an intelligent automatic tutoring system as much as it could be of help in teacher education. For example, the taxonomy design could facilitate developing teaching strategies that scaffold $21^{\text {st }}$ century skills like critical and creative thinking, critical discussion, and collaborative learning.

\section{CONCLUSIONS}

We have conceptualized teacher-learner interactions in terms of explorative action games. This conceptualization lays the basis for a cognitive speech act taxonomy, which maps conceptual change learning to special types of speech acts. The novel contribution of this approach is that language is connected to processes of collaborative knowledge building.

Our view of learning in these action games rests on three types of conceptual change: concept extension, truncation, as well as revision. We have shown how each type is connected to specific epistemic enablers, i.e. cognitive patterns used to interpret and make sense of the world. In a teacher-learner interaction, the teacher brings these enablers into play via explorative speech acts. The learner responds with a discovery speech act, potentially leading to conceptual change.

We have pointed out that conceptual change is part of the perlocution of the explorative speech act and therewith not under the full control of the speaker. The individual make-up of the learner's existing knowledge base, her learning preferences and abilities, as well as her motivational and emotive states, among others, also determine if, and if so, how learning takes place.

For future research, it will be essential to pinpoint these other factors and understand how they exactly affect learning. Only then can learning as discovery be described comprehensively and teaching and learning interactions be tailored to the needs and learning preferences of the individual learner.

\section{REFERENCES}


[1] Aristotle. (1992). Physics. Books I and II. W. Charlton (Ed.), Oxford: Clarendon Press.

[2] Bellanca, J. A. \& Brandt, S. B. (Eds.) (2010). 21st Century Skills: Rethinking how Students Learn (Leading edge 5). Bloomington, IN: Solution Tree Press.

[3] Benware, C. A. \& Deci, E. L. (1984). Quality of learning with an active versus passive motivational set. American Educational Research Journal 21, 755-765.

[4] Dahlgren, K. (1988). Naive Semantics for Natural Language Understanding. Boston: Kluwer Academic Publishers.

[5] Deci, E. L. \& Ryan, M. R. (1985). Intrinsic Motivation and Self-Determination in Human Behavior. New York: Plenum.

[6] Farrell, T. S. (2009). Talking, Listening, and Teaching: A Guide to Classroom Communication. Thousand Oaks, Calif: Corwin.

[7] Feller, S. (2013). From the Socratic Method and Self-determination Theory to Dialogic Knowledge Building. Discovering an electric circuit through deep reasoning. Manuscript submitted for publication.

[8] Fisher, R. (2005). Teaching Children to Think. (2nd ed.). Cheltenham: Stanley Thornes.

[9] Grolnick, W. S. \& Ryan, R. M. (1987). Autonomy in children's learning: An experimental and individual difference investigation. Journal of Personality and Social Psychology 52, 890-898.

[10] Hewson, P.W. (1992). Conceptual change in science teaching and teacher education. Paper presented at a meeting on "Research and Curriculum Development in Science Teaching." Madrid. Spain.

[11] Kage, M. \& Namiki, H. (1990). The effects of evaluation structure on children's intrinsic motivation and learning. Japanese Journal of Educational Psychology 38, 36-45.

[12] Koestner, R., Ryan, R. M., Bernieri, F.\& Holt, K. (1984). Setting limits on children's behavior: The differential effects of controlling versus informational styles on intrinsic motivation and creativity. Journal of Personality 52, 233-248.

[13] Levinson, S.C. (2000). Presumptive Meanings: The Theory of Generalized Conversational Implicature. Cambridge, Mass: MIT Press.

[14] Niemeier, S. (2004). Linguistic and cultural relativity: Reconsidered for the foreign language classroom. In M. Achard \& S. Niemeier (Eds.), Cognitive Linguistics, Second Language Acquisition, and Foreign Language Teaching, 95-118. Berlin, New York: Mouton de Gruyter.

[15] Paul, R.W. (1993). Critical Thinking: What Every Person Needs to Survive in a Rapidly Changing World (2nd.ed). Santa Rosa, CA: Foundation for Critical Thinking.

[16] Peccei, J. S. (1999). Pragmatics. London, New York: Routledge.

[17] Pinker, S. (2002). The Blank Slate: The Modern Denial of Human Nature. New York: Viking.

[18] Roser, S. L. \& Denton, P. (2010). Teacher Language: Professional Development Kit for Teachers of K-6 (Responsive classroom series). Turners Falls, Mass: Northeast Foundation for Children, Inc.

[19] Sacks, H., Schegloff, E. A., \& Jefferson, G. (1974). A simplest systematics for the organization of turn-taking for conversation. Language 50, 696-735.

[20] Schalley, A. C. \& Khlentzos, D. (Eds.) (2007). Mental States (Studies in language companion series v. 92-93). Amsterdam, Philadelphia: J. Benjamins Pub. Co.

[21] Searle, J. R. (1969). Speech Acts: An Essay in the Philosophy of Language. London: Cambridge University Press.

[22] Sinclair, J. \& Coulthard, M. (1975). Towards an Analysis of Discourse. Oxford: Oxford University Press.

[23] Sinclair, J. and Coulthard, M. (1992). Towards an Analysis of Discourse. In M. Coulthard (Ed.), Advances in Spoken Discourse Analysis, 1-34. London: Routledge.

[24] Thagard, P. (1992). Conceptual Revolutions (1st ed.). Princeton, N.J: Princeton University Press.

[25] Vansteenkiste, M., Ryan, R. M., \& Deci, E. L. 2008. Self -determination theory and the explanatory role of psychological needs in human well-being." In L. Bruni, F. Comim, \& M. Pugno (Eds.), Capabilities and Happiness, 187-223. Oxford, UK: Oxford University Press.

[26] Weigand, E. (2010). Dialogue: The Mixed Game (Dialogue studies 10). Amsterdam, Philadelphia: John Benjamins Pub. Co.

Sebastian Feller obtained his PhD in linguistics from the University of Muenster, Germany. He was Lecturer in English at Majan University College in Muscat, Oman, and has joined the Intuitive Interaction Technologies group of the Institute of High Performance Computing under A*STAR, Singapore, in 2011. His research interests include Dialog Analysis, Interaction Pragmatics, social robotics, social media analytics, as well as Lexical Semantics and cognitive theories of meaning. Sebastian is Secretary of the International Association of Dialogue Analysis (IADA) and Assistant Editor for the Benjamins journal Language and Dialogue as well as the book series Dialogue Studies. 